\title{
For the love of green: Between ecology and dollars
}

\begin{abstract}
This paper reviews how corporate social responsibility (CSR), in particular its environmental practices, is being mobilised in practice by companies. We discuss that the current engagement with the Anthropocene is more a marketing argument supporting a capitalist discourse, rather than an ethical approach towards business. Thus, we call for a more sustainable approach in CSR, not as a communication tool, but as a genuine response to Anthropocene conditions and shared stewardship, rather than a marketisation of CSR. We suggest the establishment of an international CSR certification entity that would advise companies in CSR practices in the Anthropocene Earth.
\end{abstract}

Keywords: corporate social responsibility, Anthropocene, stewardship

\section{Introduction}

The corresponding author worked for a prestigious French financial consulting company for a couple of years during his $\mathrm{PhD}$. He was in one of the most reputable offices of the conglomerate, dedicated to portfolio decision-making. One day, after a meeting on portfolio diversification, the senior manager put forward the names of several companies well-known for their green policies. When the corresponding author inquired about the 
motivation for including green options in the portfolio strategy - in relation to the CSR practices of the selected companies - the executive director suggested that green investment was a way of making money: "If the customers want green I give them green ... I love green, green is the colour of the dollar".

This episode motivated us to reflect on the use of corporate social responsibility (CSR) in organisations. In this paper, we examine how CSR has been constructed in literature and in practice to connect an organisation to the environment in a positive way, though it is often used to mean "business as usual". We argue that management scholars should take into consideration the Anthropocene issues, to rethink CSR as theory and practice. CSR should not be left to companies to comply with, it should be part of a wider supernational organisation of experts that could provide a significant form of effective climate/environment feedback, and change the discourses and narratives in which it is currently embedded.

CSR is a broad umbrella of self-regulatory mechanisms covering economic, social and environmental domains and involves communicating the social and environmental effects of a company's economic actions to particular interest groups. 
To demonstrate the necessity of establishing a supernational body of experts, we focus on the failure of CSR in relation to environmentalism and carbon emissions, and its implications for the Anthropocene. The Anthropocene is a period in which human activities have visibly compromised the Earth's global equilibrium (Steffen, Crutzen and McNeill 2007). Since the industrial revolution, humans have "consciously or unwittingly alter[ed] the surrounding environment, to extract minerals, generate energy, make food and shelter, provide global communication, and so on" (Zalasiewicz et al. 2017: 2). Thus, in the Anthropocene, humans not only influence the Earth, but also have to live with the consequences, which seems to have been dismissed in current CSR practices. Many environmental changes were triggered and created by industries, and companies are ignoring the consequences (Bonneuil and Fressoz 2016).

Currently, companies are stemming from a world dominated by a capitalist logic concerned predominantly with making money (Angus 2016; Haraway 2016), which creates challenges related to urbanisation (Colebrook 2016), waste management (Hird 2017), ethical and political struggles (Szerszynski 2010), dramatic weather events, rising sea-levels, food and water shortages, political conflicts and imperialist politics (Last 2015), massive deregulation, the rise of populism and explosion of inequalities (Latour 2017), and extreme biodiversity loss (Zalasiewicz et al. 2019). Companies are doing very little to mitigate these issues, as they are working to a logic of constant growth, which is 
not sustainable in the long run: critical resources are finite, and there is a constant degradation of ecosystems and an "erosion of the planet's capability to absorb our wastes", generating a sustainability crisis (Steffen et al. 2011: 739). Companies, organisations and human ecosystems are now part of the Earth system, becoming geology themselves (Latour 2017).

Hence, we criticise the current CSR practices, which have been "marketised" in the field of accounting to make the environment visible through numbers to present their "green" activities to the stakeholders, and we criticise how this communication to external stakeholders is frequently mere rhetoric, failing to engage and address the issues in the Anthropocene.

Global environmental change is driven largely by the unwanted consequences of commerce and industry. Altering the procedures and priorities of commerce and industry is prerequisite to mitigating those environmental pressures. Globally, commerce and industry are driven by the profit motive, or "bottom line", and although companies claim to have a "triple bottom line", this serves to control the adverse side-effects through national and international regulations, rather than purposively change the practices to reduce the "Great Acceleration". 


\section{CSR and practices of making environment visible}

Corporate social responsibility is an elusive concept whose significance has regularly changed in its history (Carroll 1999), operating with open rules of application, and which can be summed up as businesses "bearing a responsibility to society and a broader set of stakeholders beyond its shareholders" (Wang et al. 2016: 534). CSR usually refers to practices that are meant to do something good for society, rather than merely discussing its possibility (Aras and Crowther 2009), built on a large ideological spectrum ranging from initiatives focused on conservative values (e.g. Hobby Lobby and Chick-fil-A in the USA) to very progressive liberal values (e.g. Ben and Jerry's ice cream).

Since we focus on CSR activities in relation to ecology, we present some examples of the failed accountability of companies in relation to carbon emissions and fossil-fuel exploitation.

Financial and external reports are used to make visible CSR practices, indicating an organisation's ecological involvement, alongside the return on investment of CSR activities and issues related to the accountability of organisations (O'Sullivan and O’Dwyer 2015). For example, carbon emission permits and reportings are mechanisms through which accounting as calculative mechanisms are used to estimate environmental issues (Hopwood 2009), making nature visible through accounting numbers. 
CSR lies between (internal) financial pressures and (external) public relations. This tension makes CSR practices challenging and complex, since there are different variables that need to be taken into consideration, such as: affordable costs; adoption within the firm of new forms of measurements; and incentives to motivate ethical, social and environmental behaviours (Roberts 2003). Who is responsible for what, the minimum acceptable standards, and the goals of CSR are constantly evolving (Gilbert, Rasche and Waddock 2011).

This situation opens the door for companies to consider CSR with a cynical business attitude, using it as an instrumental logic, as in the case of BP after the Deepwater Horizon tragedy.

In BP's CSR report in 2010 (BP 2010), the company highlights that the volume of oil spilled (in million litres) was 1.7, whilst it was 1.2 in 2009 and had actually decreased compared to 2008 since it was reported as being 3.4! Direct carbon dioxide, indirect carbon dioxide, direct methane, and direct greenhouse gas (GHG) emissions are reported as stable or even decreasing in value. How can this be stated after the worst oil spill in history? The company writes (p. 8): 
"Although there are several third-party estimates of the flow rate or total volume of oil spilled from the Deepwater Horizon, we believe that no accurate determination can be made or reported until further information is collected and the analysis, such as the condition of the blowout preventer, is completed. Once such determination has been made, we will report on the spill volume as appropriate."

The following year's report (BP 2011) does not provide any update. Ernst and Young, the auditors of the reports, made the following comment (p. 7):

"BP [in the tables of values related to environmental impact] refers to studies that have been undertaken to help understand the impact on habitats. Whilst it is clear that a wide range of activities are under way or have been completed, the full analysis of the various studies is pending, and BP should provide updates in due course."

In BP's 2012 report, the values presented are the same. In addition, a whole chapter describes the achievements in cleaning up the Gulf of Mexico (BP 2012). "According to data from NOAA, commercial seafood landings in the Gulf in 2011 reached their highest levels since 2000, although the results varied by state and by species." However, it is not 
explained what varied, nor by how much.

CSR has also been used by corporations to benefit from tax deductions and to lobby for lowering tax (The Economist 2016). Large corporations exert substantial political influence on decisions concerning climate change policies, since they propose solutions that are aligned with their business model and sources of income, rather than actual measures to decrease their impact in the Anthropocene, thus making the Earth system vulnerable. This opportunistic way of using CSR has been criticised by many environmentalist groups working to identify non-green companies that claim to be green by making nature visible and emphasising the positive externalities, while polluting and hiding the detrimental effects of their activities through numbers. In response, environmentalist groups have tried to draw public attention to these problems and urged shareholders to disinvest from holdings in coal, oil and gas (The Economist 2015).

CSR has been contested also as a greenwashing practice (Kewalramani and Sobelsohn 2012; Laufer 2003), since some businesses use CSR claims as marketing tools (Costas and Kärreman 2013) in a deceptive way, using the label "eco-friendliness" to sell more products. CSR and the use of such terms as "eco-friendly," "organic," "natural," and "green" are everyday examples of how brands create a "halo effect" (The Economist 
2015), whereby a product can earn consideration from consumers by leveraging on the invitation for customers to indirectly contribute to a good cause by buying the product.

It is worth mentioning that recent polluting scandals are not related to a specific political regime, since they occurred in North America (BP Deepwater scandal), South America (PDVSA oil spilling in Venezuela) (Zerpa 2018) and Asia (e.g. in Vietnam with the toxic spill from a steel plant belonging to Taiwan's Formosa Plastic Group, which killed all the fish in the affected coastline) (The Guardian 2017); and China, in the case of emission monitoring fraud in which officials manipulated sensory equipment to distort pollution readings (Stanway 2018)). Polluting scandals also occurred across various industries, such as fashion supply chains (in which factories supplying famous brands have been spilling toxic materials into the waters) (for in-depth reading, Siegle 2011), fossil-based and agriculture, among others. However, these practices are related to the current economic models of production and consumption that are exhausting the Earth system, creating resource shortages and environmental degradation, pressuring the poorer groups of society, and causing long-term irreversible damage (Steffen et al. 2011). In this context, CSR reporting allows stakeholders to "see", make visible and "value" the company's CSR policy in accounting records, but it can be construed as insincere (Laufer 2003) from a societal point of view (Roberts 2003), and the good intentions of some 
organisations using CSR practices are overshadowed by more predatory ones in which CSR is used to increase market value and profits.

Instead, as Latour (2017) suggests, companies need to bring the Earth system into the construction of a multitude of beings, in which different actors have a performative role in engaging with the Anthropocene. We explain the performative concept in the next section.

\section{CSR as a discourse}

Although CSR might be "business as usual", discourses concerning CSR practices can potentially stimulate a positive social change, even if this is not fully reflected in organisational practices (Christensen, Morsing and Thyssen 2013). However, as we have discussed in the previous section, CSR can become a form of communication that serves as a stratagem to obtain legitimacy (Roberts 2003) to help sponsor a company's business activities (Hopwood 2009). Currently, this is a passing fad as it is not systematically embedded in organisational working practices (Gond et al. 2012).

As far as making "nature visible" is concerned, CSR practices seem insufficient in trying to encourage corporations to engage in virtuous behaviours, as there is an implicit synonymy between making visible the absence of a bad impact on environment and doing 
something valuable towards stopping climate change.

Discourses on CSR practices are performed to create a rhetoric around organisational practices, in order to: communicate values that employees need to embrace, transform CSR into a tool for managing employees (Costas and Kärreman 2013) and improve relationships within the community (Kazmi, Leca and Naccache 2016).

Instead, to frame positive changes, we need to create discourses that are performative and have a positive impact, and we need to have "performative utterances", sentences in which saying something means doing something (Austin 1975).

Given the critiques evoked in the previous section, it is legitimate to question further to what extent CSR could become performative for good practices. As we have analysed, concerns have been raised by organisational scholars that CSR practices are implemented by corporations that are doing business as usual, are morally empty, act predominantly for their own and their shareholders' gain (see the review by Kazmi, Leca and Naccache 2016), and to control the behaviour of their employees. In this context, how can anyone be sure that well-intentioned discourse can really generate positive actions?

\section{Towards a performative CSR}


Macintosh et al. (2000) and Mattessich (2003) indicate that accounting is a way of thinkinglstructuring a relationship with the economic environment. However, if accounting in terms of representing nature fails to refer to a given reality, it might circulate in a self-referential model in which representing Anthropocene through CSR is not necessarily good enough to engage with such reality (e.g. BP reporting), not good enough to perform its discourse within an organisation and society (e.g. greenwashing) because nature is considered an "outsider", and dividing nature from humans creates a big divide (Latour 1993). Companies are currently considering CSR practices "inside the organisation" as separate from outside ecology, and this creates the possibility of predatory practices, as nature is not considered part of the same ecosystem, but outside of it.

Our article calls for a different and improved CSR in relation to its role in the Anthropocene, which requires to actively think about nature as an actor to be included in organisational activities rather than being seen as "something out there". This requires a different economic system that incentivises CSR as a tool for sustainable growth rather than serving the new-liberal marketing and accounting practices that are irreversibly changing the Earth system. It is necessary to research and apply new practices and economic systems that are moving away from the money-making logic and from the idea of exponential and infinite growth, as the resources are finite. For example, new theories 
on "slow innovation" and "slow growth" need to be developed to suggest alternatives to the current economic logic.

Furthermore, in the current economic model, we need to develop a "global stewardship" to avert or contain local collapse (Steffen et al. 2011), to avoid greenwashing or misleading representations. In fact, companies' impact on Earth system functioning cannot be resolved by asking companies to comply with norms and standards, nor is it a task to be performed only by environmental activities. Instead, a homogenous supernational cooperation and the establishment of an international CSR institute are needed. The international CSR institute would have the task of authoritatively monitoring the effects of particular CSR practices, developing new practices in response to those that are not working, and publicly recognising those companies that are complying with a “CSR stewardship".

For future research, we suggest the development of theories for a new CSR stewardship which could perform CSR discourses, and encourage companies to develop more benign and less environmentally harmful practices. We also suggest carrying out tests on a selected sample, ideally in Official Development Assistance (ODA) compliant countries, as companies in these regions are rushing to grow as fast as possible, and are frequently 
using polluting practices. If the practices could work here, they could potentially be replicated everywhere. 


\section{References}

Angus-Leppan H (2016) Facing the Anthropocene: Fossil Capitalism and the Crisis of the Earth System. Reprint. London: Monthly Review Press.

Aras G and Crowther D (2009) Corporate sustainability reporting: A study in disingenuity? Journal of Business Ethics 87(1): 279-288.

Austin JL (1975) How to Do Things with Words: The William James Lectures Delivered in Harvard University in 1955. Oxford, UK: Oxford University Press.

Bonneuil C and Fressoz J-B (2016) The Shock of the Anthropocene: The Earth, History and Us. London: Verso.

British Petroleum (BP) 2010. Sustainability Review 2010. Available at https://www.bp.com/content/dam/bp/business-sites/en/global/corporate/pdfs/ sustainability/archive/archived-reports-and-translations/2010/bp_sustainability_ review_2010.pdf(accessed 15 May 2019).

BP 2011. Sustainability Review 2011. Available at https://www.bp.com/content/dam/ bp/business-sites/en/global/corporate/pdfs/sustainability/archive/archived-reportsand-translations/2011/bp_sustainability_review_2011.pdf (accessed 15 May 2019).

BP 2012. Sustainability Review 2012. Available at https:/www.bp.com/content/dam/ bp/business-sites/en/global/corporate/pdfs/sustainability/archive/archived-reportsand-translations/2012/bp-sustainability-review-2012.pdf (accessed 15 May 2019). 
Carroll AB (1999) Corporate social responsibility: Evolution of a definitional construct. Business \& Society 38(3): 268-295.

Christensen LT, Morsing M and Thyssen O (2013) CSR as aspirational talk. Organization 20(3): 372-393.

Colebrook CM (2016) Sex and the (Anthropocene) city. Theory, Culture \& Society $34(2-3) 39-60$.

Costas J and Kärreman D (2013) Conscience as control: Managing employees through CSR. Organization 20(3): 394-415.

Gilbert DU, Rasche A and Waddock S (2011) Accountability in a global economy: The emergence of international accountability standards to advance corporate social responsibility. Business Ethics Quarterly 21: 23-44.

Gond JP, Grubnic S, Herzig C and Moon J (2012) Configuring management control systems: Theorizing the integration of strategy and sustainability. Management Accounting Research 23(3): 205-223. Available at https://doi.org/10.1016/ j.mar.2012.06.003 (accessed 15 May 2019).

Haraway DJ (2016) Staying with the Trouble: Making Kin in the Chthulucene (Experimental Futures: Technological Lives, Scientific Arts, Anthropological Voices). Durham, NC: Duke University Press.

Hird MJ (2017) Waste, environmental politics and dis/engaged publics. Theory, Culture \& Society 34(2-3): 187-209. 
Hopwood AG (2009) Accounting and the environment. Accounting, Organizations and Society 34(3): 433-439.

Kazmi BA, Leca B and Naccache P (2016) Is corporate social responsibility a new spirit of capitalism? Organization 23(5): 742-762.

Kewalramani D and Sobelsohn RJ (2012) Greenwashing: Deceptive business claims of "eco-friendliness". Forbes, Mar 20, 2012. Available at https://www.forbes. com/sites/realspin/2012/ 03/20/greenwashing-deceptive-business-claims-of-ecofriendliness/\#d5a21033d9a6_(accessed 15 May 2019).

Last A (2015) We are the world? Anthropocene cultural production between geopoetics and geopolitics. Theory, Culture \& Society 27(2-3) 254-266.

Latour B (1993) We Have Never Been Modern. Cambridge, Mass: Harvard University Press.

Latour B (2017) Facing Gaia: Eight Lectures on the New Climatic Regime. Cambridge, UK: Polity Press.

Laufer WS (2003) Social accountability and corporate greenwashing. Journal of Business Ethics 43(3): 253-261.

Macintosh NB, Shearer T, Thornton DB and Welker M (2000) Accounting as simulacrum and hyperreality: Perspectives on income and capital. Accounting, Organizations and Society 25(1): 13-50.

Mattessich R (2003) Accounting representation and the onion model of reality: A 
comparison with Baudrillard's orders of simulacra and his hyperreality. Accounting, Organizations and Society 28(5): 443-470.

O’Sullivan N and O'Dwyer B (2015) The structuration of issue-based fields: Social accountability, social movements and the Equator Principles issue-based field. Accounting, Organizations and Society 43: 33-55.

Roberts J (2003) The manufacture of corporate social responsibility: Constructing corporate sensibility. Organization 10(2): 249-265.

Siegle L (2011) To Die For: Is Fashion Wearing Out the World? London: Fourth Estate.

Stanway D (2018) China's environment ministry warns against monitoring fraud. Reuters. August 31, 2018. Available at https://www.reuters.com/article/us-chinapollution-monitoring/chinas-environment-ministry-warns-against-monitoringfraud-idUSKCN1LG05G (accessed 15 May 2019).

Steffen W, Crutzen PJ and McNeill JR (2007) The Anthropocene: Are humans now overwhelming the great forces of nature? AMBIO: A Journal of the Human Environment. 36(8): 614-621 https://doi.org/10.1579/00447447(2007)36[614:TAAHNO]2.0.CO;2.

Steffen W, Persson Å, Deutsch L, Zalasiewicz J, Williams M, Richardson K, Crumley C et al. (2011) The Anthropocene: From global change to planetary stewardship. Ambio 40(7): 739-761. https://doi.org/10.1007/s13280-011-0185-X. 
Szerszynski B (2010) Reading and writing the weather: Climate technics and the moment of responsibility. Theory, Culture \& Society 27(2-3): 9-30.

The Economist (2015) Corporate social responsibility: The halo effect: Do-gooding policies help firms when they get prosecuted. Jun 25th 2015.

The Economist (2015) Divestment campaigns: Fight the power: Investors are being pressed to sell their holdings in coal, oil and gas. Jun 25th 2015.

The Economist (2016) Scumpeter: Social saints, fiscal fiends: Opinions vary on whether firms can be "socially responsible" while avoiding taxes. Jan 2nd 2016.

The Guardian (2017) 'We are jobless because of fish poisoning': Vietnamese fishermen battle for justice. Aug 14, 2017. Available at https://www.theguardian.com/globaldevelopment/2017/aug/14/vietnamese-fishermen-jobless-fish-poisoning-battlejustice (accessed 15 May 2019).

Wang H, Tong L, Takeuchi R and George G (2016) Corporate social responsibility: An overview and new research directions. Thematic issue on corporate social responsibility. Academy of Management Journal 59(2): 534-544.

Zalasiewicz J, Waters C, Williams M and Summerhayes C (2019) The Anthropocene as a Geological Time Unit: A Guide to the Scientific Evidence and Current Debate. Cambridge, UK: Cambridge University Press.

Zalasiewicz J, Williams M, Waters CN, Barnosky AD, Palmesino J, Rönnskog AS, Edgeworth M et al. (2017) Scale and diversity of the physical technosphere: A 
geological perspective. Anthropocene Review 4(1): 9-22. Available at https://doi.org/10.1177/2053019616677743 (accessed 15 May 2019).

Zerpa F (2018) Venezuela is leaking oil everywhere. Bloomberg, 24 November 2018. Available at https://www.bloomberg.com/news/features/2018-11-24/venezuela-isleaking-oil-everywhere-and-making-a-dangerous-mess (accessed 15 May 2019). 